\title{
Developmental Aspects of Escherichia coli-Induced Innate Responses in Rat Renal Epithelial Cells
}

\author{
ÅSA LAESTADIUS, TOMAS SÖDERBLOM, ANITA APERIA, AND \\ AGNETA RICHTER-DAHLFORS \\ Department of Woman and Child Health [Å.L., A.A.] and Microbiology and Tumor Biology Center [T.S., \\ A.R.-D.], Karolinska Institute, 17176 Stockholm, Sweden
} \begin{abstract}
ABS
Renal scarring after pyelonephritis is common in infancy. In
this experimental study performed on tissue from 10-d-old infant and 40-d-old pubertal rats, several aspects of the renal innate immune response to a pyelonephritogenic strain of $\alpha$-hemolysinexpressing Escherichia coli were compared. The kidney typically responds to urinary tract infection with release of proinflammatory cytokines, e.g. IL-6. Basal production of IL-6 from 10-d-old renal cortical tissue was approximately $20 \%$ of that from $40-d-$ old tissue. Six-hour incubation in the presence of supernatant from the $E$. coli culture caused an approximately 15 -fold increase of IL-6 release in 10-d-old tissue and a 5-fold increase in 40-d-old tissue. The absolute level of IL-6 release in stimulated tissue was, however, significantly lower at $10 \mathrm{~d}$ than at $40 \mathrm{~d}$. Lipopolysaccharide, the most immunogenic component of $E$. coli, signals via Toll-like receptor 4 . Reverse transcriptase PCR performed on outer renal cortex indicated that expression of Toll-like receptor 4 mRNA was similar in both ages. Microdissection studies revealed that Toll-like receptor 4 mRNA was
\end{abstract}

expressed in proximal tubules but not in glomeruli. The exotoxin $\alpha$-hemolysin, expressed by a majority of uropathogenic E. coli isolates, stimulates IL-6 release via an alternative pathway that signals via intracellular calcium oscillations. We conclude that the higher susceptibility to pyelonephritic scarring is unlikely related to immaturity of innate immune system, as measured by cellular release of IL-6. Instead, the underlying mechanisms for pyelonephritic scarring are most likely multifactorial and may be mainly attributed to anatomic immaturity of the urinary tract. (Pediatr Res 54: 536-541, 2003)
HlyA, $\alpha$-hemolysin
LPS, lipopolysaccharide
RPT cell, rat proximal tubule cell
RT-PCR, reverse transcriptase PCR
TLR4, Toll-like receptor 4
UTI, urinary tract infection

Abbreviations
Pyelonephritis is more common in children than in adults, and children are more prone to develop renal scarring after infection. Children younger than 3 years old are particularly susceptible to the development of renal scars or hypoplastic kidneys postinfectiously $(1,2)$. This age-dependent difference has been ascribed to a higher incidence of reflux (3) or different strains of bacteria. Whether the increased vulnerability of the kidney to UTI in infants and young children may also be caused by an immature immunologic response is not known.

The host immunologic response is generally considered to be of utmost importance for the outcome of UTI. Epithelial

Received April 2, 2002; accepted January 7, 2003

Correspondence: Åsa Laestadius, M.D., Research Lab, Q2:09, Astrid Lindgren Children's Hospital, 17176 Stockholm, Sweden; e-mail: asa.laestadius@ks.se

Supported by grants from The Swedish Research Council (A.A., A.R.-D.), Tielman Foundation, Sällskapet Barnavård, Samariten Foundation, and Ronald McDonald Barnfond. A.R.D. is a recipient of special grants from the Swedish Foundation for Strategic Research (SSF).

DOI: 10.1203/01.PDR.0000081763.37767.6B cells lining the urinary tract elicit the innate immune system by secreting proinflammatory cytokines and chemokines on microbial stimulation. In this context, secreted IL-6 and IL-8 have been shown to play an important role for clearance of UTI (4, 5).

Bacteria can activate the innate immune system by various mechanisms. Cellular recognition of bacterial LPS, which signals via TLR-4, is generally considered to be of major importance for activation of the immune system (6). Recent studies have suggested that sublethal concentrations of bacterial toxins will, by activation of signaling pathways in the host cell, also elicit an innate immune response (7). An example of this is the observation that the exotoxin HlyA, secreted from Escherichia coli, induces a low-frequency calcium oscillation, which causes the release IL-6 and IL-8. Approximately 50\% of the uropathogenic E. coli strains express $\operatorname{HlyA}(8,9)$, and this toxin is often associated with severe pyelonephritis $(10,11)$.

In this study, we examined whether there is an agedependent difference in the innate immune response of the 
renal epithelium that may explain the increased vulnerability to pyelonephritis in children. Rat renal cortical tissue or primary culture of RPT cells have been exposed to supernatant from HlyA-expressing E. coli, and the release of IL-6 and intracellular calcium have been recorded. The expression of TLR4 and CD14 mRNA in RPT cells and cortical slices has been studied.

\section{METHODS}

Bacteria. Uropathogenic E. coli strain ARD6 (serotype O6:K13:H1, World Health Organization designation Su 4344/ 41) (12) was cultured overnight in Luria-Bertani (LB) medium at $37^{\circ} \mathrm{C}$. This strain expresses the exotoxin HlyA (7). The bacterial culture was centrifuged, and the supernatant was sterile-filtered through a Millipore filter (Minisart, $0.2 \mu \mathrm{m}$, Sartorius AG, Göttingen, Germany). The bacterial supernatant was assayed for hemolytic activity as described (13). A dilution giving $60 \%$ hemolysis of $2.5 \%$ sheep erythrocyte suspension was defined as 1000 hemolytic units (HU). Ten microliters of supernatant corresponds roughly to $100 \mathrm{HU}$. The sterilized supernatant was kept on ice until used (15 min to $4 \mathrm{~h}$ ).

Preparation of proximal tubule cells. The animal experiments were performed after approval from the local ethical committee for animal experimentation. RPT cells were prepared from kidneys from 10- and 40-d-old Sprague-Dawley rats as previously described (14). Cells were cultured in supplemented Dulbecco's minimal essential medium (DMEM: 20 $\mathrm{mM}$ HEPES, $24 \mathrm{mM} \mathrm{NaHCO}{ }_{3}, 10 \mu \mathrm{g} / \mathrm{mL}$ penicillin, 10 $\mu \mathrm{g} / \mathrm{mL}$ streptomycin, and $10 \%$ FBS) on glass coverslips for $48 \mathrm{~h}$ in $5 \% \mathrm{CO}_{2}$ at $37^{\circ} \mathrm{C}$. Cells were serum starved ( $\left.1 \% \mathrm{FBS}\right)$ and cultured in the absence of antibiotics for $24 \mathrm{~h}$ before experiment.

Renal cortical slices for IL-6 measurements. Ten- and 40-d-old Sprague-Dawley rats were bled by cutting the abdominal aorta, the kidneys were removed, and $150-\mu \mathrm{m}$-thick slices were taken under sterile conditions from the superficial renal cortex using a microtome. The tissue slices were incubated at $37^{\circ} \mathrm{C}, 5 \% \mathrm{CO}_{2}$, for $6 \mathrm{~h}$ in $300 \mu \mathrm{L}$ of supplemented DMEM (20 $\mathrm{mM}$ HEPES, $24 \mathrm{mM} \mathrm{NaHCO}{ }_{3}, 1 \mu \mathrm{M}$ butyrate) with or without $20 \mu \mathrm{L} / \mathrm{mL}$ supernatant from $E$. coli strain ARD6 or $10 \mathrm{ng} / \mathrm{mL}$ IL-1 $\beta$ (positive control). Supernatant from the incubation medium was collected, pooled and frozen at $-80^{\circ} \mathrm{C}$ until analyzed. At the end of experiment, the cortical slices were homogenized in $20 \mathrm{mM}$ Tris- $\mathrm{HCl}$ on ice for protein measurement (Bio-Rad Laboratories, Hercules, CA, U.S.A.).

IL-6 measurements. IL-6 in tissue culture supernatants was analyzed by ELISA according to the manufacturer's instructions (Biotrak; Amersham, Bioscience, Europe GMBH, Uppsala, Sweden). Because this was a comparative analysis, tissue from 10- and 40-d-old rats was always examined in parallel. For each protocol we used six to nine parallel experiments. The absorbance values were correlated to the protein content of each sample, and the values are presented as picomoles of IL-6 per milligram of protein.

Preparation of renal cortical slices, tubules, and glomeruli for RT-PCR. Kidney perfusion and tubule and glomeruli microdissection was performed as described earlier (15). Briefly, the left kidney in 10- or 40-d-old Sprague-Dawley rats was perfused and rinsed with $10 \mathrm{~mL}$ of cold Ringer's solution, followed by $40 \mathrm{~mL}$ of cold collagenase solution containing (in $\mathrm{mM}) \mathrm{NaCl}, 137 ; \mathrm{KCl}, 5 ; \mathrm{MgSO}_{4}, 0.8 ; \mathrm{Na}_{2} \mathrm{PO}_{4}, 0.33 ; \mathrm{KH}_{2} \mathrm{PO}_{4}$, $0.44 ; \mathrm{CaCl}_{2}, 1 ; \mathrm{MgCl}_{2}, 1$; Tris- $\mathrm{HCl}, 10 ; 0.05 \%$ collagenase, and $0.1 \%$ BSA, $\mathrm{pH} 7.4$ at $4^{\circ} \mathrm{C}$. Kidneys were removed and cut along the corticopapillary axis into small pyramids that were incubated at $35^{\circ} \mathrm{C}$ for $10 \mathrm{~min}$ in the same collagenase solution bubbled with $95 \% \mathrm{O}_{2}-5 \% \mathrm{CO}_{2}$. Tubules and glomeruli were manually dissected at $4^{\circ} \mathrm{C}$ under a stereomicroscope, pooled, and immediately frozen on dry ice. In addition, total RNA was extracted from a $150 \mu \mathrm{m}$ thick slice of the outer renal cortex. Previous to this procedure the kidneys were perfused with Ringer's solution to remove all blood cells. The slice was immediately homogenized in lysis buffer (Sigma Chemical Co., St. Louis, MO, U.S.A.) and frozen on dry ice until total RNA was extracted with the TriZol reagent (Invitrogen, Carlsbad, CA, U.S.A.).

Detection of TLR4 and CD14 by RT-PCR. CDNA was synthesized using the First Strand Synthesis Kit for RT-PCR (Roche Diagnostics Scandinavia AB, Bromma, Sweden) using $4 \mu \mathrm{g}$ of total RNA according to the manufacturer's instructions. RT-PCR was performed with primers for rat Toll protein (sense, 5'-GCCGGAAAGTTATTGTGGTG-3'; antisense, 5'TCCCACTCGAGGTAGGTGTT-3'), yielding a 205-bp product, and rat CD14 (sense, 5'-CTTGTTGCTGTTGCCTTTGA3'; antisense, 5'-CGTGTCCACACGCTTTAGAA-3'), giving a product of $214 \mathrm{bp}$. As a control, rat $\alpha$-tubulin (sense, 5'GCCTGCTGGGAGCTCTACT-3'; antisense, 5'-GTGGGTTCCAGGTCTACGAA-3') was used, yielding a product of 164 bp. One millimolar of each primer was used in the amplification reaction, which was run according to the following protocol: one cycle at $94^{\circ} \mathrm{C}, 4 \mathrm{~min} ; 25,28,31$, or 35 cycles at $94^{\circ} \mathrm{C}, 45 \mathrm{~s}, 60^{\circ} \mathrm{C}, 45 \mathrm{~s}$, and $72^{\circ} \mathrm{C}, 1 \mathrm{~min}$; and one cycle at $72^{\circ} \mathrm{C}$, $10 \mathrm{~min}$. The PCR products were analyzed on a $1.5 \%$ agarose gel using water or RNA from the above-mentioned RNA samples as negative controls. The rat Toll sequence shows high homology to the TLR4 sequence published for mouse and human when a BLAST (National Center for Biotechnology Information, National Institutes of Health, Bethesda, MD, U.S.A.) search is performed.

Measurement of intracellular calcium. RPT cells were incubated with $30 \mu \mathrm{M}$ fura-2 acetyl methyl ester (Molecular Probes, Leiden, The Netherlands) in P medium (in $\mathrm{mM}: \mathrm{NaCl}$, 100; $\mathrm{KCl}, 4$; HEPES, 20; $\mathrm{NaHCO}_{3}, 25 ; \mathrm{CaCl}_{2}, 1 ; \mathrm{MgCl}_{2}, 1.2$; $\mathrm{NaH}_{2} \mathrm{PO}_{4} \cdot \mathrm{H}_{2} \mathrm{O}, 1$; and D-glucose, 10) for 30-60 min before the intracellular calcium measurements. Ratiometric imaging was performed as previously described (7). Cells were excited every $60 \mathrm{~s}$, which correspond to a Nyquist frequency of 8.35 $\mathrm{mHz}$. The cells grew in cluster of 5-100 cells. Generally clusters of 15-35 cells were chosen for calcium recordings. The cells were exposed to 30,50 , or $100 \mu \mathrm{L} / \mathrm{mL}$ of $E$. coli supernatant, two to three experiments for each concentration, 15-35 cells in each experiment.

Power-spectrum analysis and statistical analysis. A powerspectrum analysis was performed as previously described (7). Briefly, the single-cell-recording calcium oscillations are analyzed to produce a spectrum in which the peaks correspond to the different frequencies present in the original data. The 
dominant peak was determined by comparing the relative power of the peaks in the spectrum. This was calculated by determining the area between the two extremes closest to the peak, divided by the total area of the power spectrum.

Statistical analysis was performed using $t$ test. All values are presented as mean \pm SEM.

\section{RESULTS}

Immature renal tissue is less responsive to bacterial infections compared with adult tissue. To study whether there is an age-dependent difference in innate immune response to bacterial exposure, slices from the outer $150 \mu \mathrm{m}$ of renal cortex from 10- and 40-d-old rat kidneys were exposed to supernatant from the E. coli strain ARD6, which in addition to shed LPS contains HlyA. After $6 \mathrm{~h}$ of incubation the release of IL-6 into the culturing medium was measured using ELISA. Tissue from 10- and 40-d-old rats was always studied in parallel. In nonstimulated cells the level of IL-6 release in 10-d-old tissue was only approximately $20 \%$ of what was released in 40-d-old tissue $(7 \pm 2 \mathrm{pmol} / \mathrm{mg}$ and $43 \pm 13 \mathrm{pmol} / \mathrm{mg}$, respectively). This difference was highly significant (Fig. 1). After exposure to $E$. coli supernatant, a marked increase in IL-6 secretion was observed in both age groups. The relative increase was larger from 10- than from 40-d-old tissue (15- and 5-fold, respectively). The absolute value for IL-6 release from 10-d-old tissue did, however, remain significantly lower than the IL- 6 release from 40 -d-old tissue ( $100 \pm 24 \mathrm{pmol} / \mathrm{mg}$ in 10-d-old compared with $200 \pm 31 \mathrm{pmol} / \mathrm{mg}$ in 40 -d-old). IL- $1 \beta$ is well known to stimulate IL-6 release. In each age group IL- $1 \beta$ induced levels of IL-6 release similar to those induced by $E$. coli supernatant.

HlyA-induced intracellular calcium oscillations occur at the same frequency in 10- and 40-d-old RPT cells. We have previously shown that the supernatant from HlyA-expressing E. coli, as well as purified HlyA, can induce low-frequency calcium oscillations in rat RPT cells. This second-messenger response was shown to induce a release of IL-6 and IL-8 (7). To test whether there is an age-dependent difference in HlyAinduced calcium oscillations, primary cultures of RPT cells from 10- and 40-d-old rats were loaded with the calciumsensitive dye fura- 2 and exposed to different concentrations of

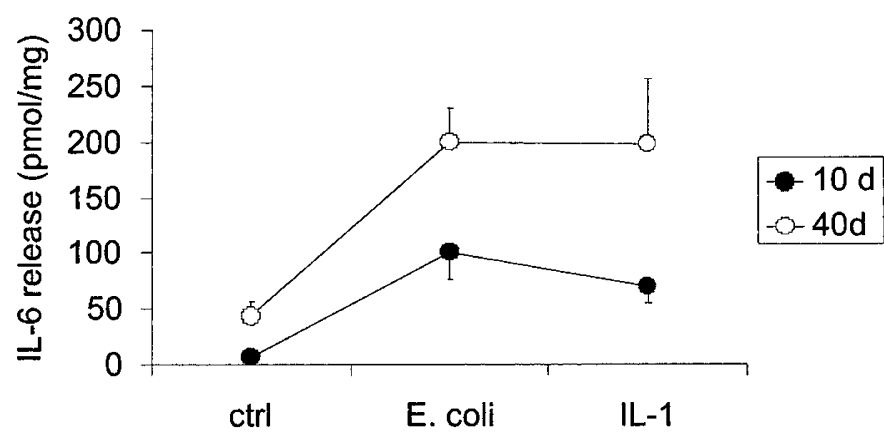

Figure 1. IL-6 release from renal cortical slices from 10-d-old rats $(\bullet)$ and 40-d-old rats (O) were exposed to HlyA-containing supernatant from E. coli or IL- $1 \beta$ for $6 \mathrm{~h}$. The values are presented as $\mathrm{pmol} / \mathrm{mg}$ tissue. Slices from 10 - and 40 -d-old rats were always run in parallel. The values presented are the mean of six to nine determinations \pm SEM. A $t$ test was performed and all compared data were significant $(p<0.005)$.
E. coli supernatant. The calcium response was recorded with a cell-imaging system.

Single-cell recordings showed that cells from both 10- and 40-d-old rats predominantly responded with calcium oscillations when exposed to $30-50 \mu \mathrm{L} / \mathrm{mL}$ HlyA-containing E. coli supernatant, and predominantly responded with a sustained elevated level of calcium that was followed by cell lysis and cell death when exposed to higher concentrations of 100 $\mu \mathrm{L} / \mathrm{mL}$ (Fig. 2, $A$ and $B$ ). The number of oscillating cells decreased when exposed to higher concentrations of HlyAcontaining E. coli supernatant, whereas the number of cells responding with sustained elevated level of calcium increased (Fig. 2, $C$ and $D$ ). An effect of the supernatant on intracellular calcium was noted in approximately $60 \%$ of cells, regardless of the concentration of supernatant used. The calcium response was generally observed in cells in the periphery of a cluster, and the percentage of the responding cells was identical in both age groups (10-d-old, 66\%; 40-d-old, 63\%). The oscillations were examined with spectral analysis to analyze at which frequency the oscillations occurred. This analysis indicated that there was one dominant peak in each spectrum (relative power, approximately 50\%), and this peak corresponded to a periodicity in the 11- to 12-min range (Table 1). The periodicity was not significantly different in the 10- and 40-d-old cells, and we could not observe any age-dependent differences in time to onset of calcium oscillations, or the duration of oscillations.

Proximal tubule cells are LPS-responsive because of expression of TLR4. LPS is considered to be the major microbial inducer of IL-6. This effect is generally agreed to be mediated via TLR4 and its coreceptor CD14 (6). To study whether the difference in IL-6 release from 10- and 40-d-old tissue may be related to different expression of TLR4 and CD14, a semiquantitative RT-PCR study was performed. Total RNA was extracted from superficial rat renal cortical slices from 10- and 40 -d-old rats, and $\alpha$-tubulin was run in parallel. TLR4 and CD14 mRNA were expressed in both 10- and 40-d-old slices. Compared with the housekeeping gene, $\alpha$-tubulin, the expression of TLR4 and CD14 were expressed in similar amount in 10- and 40-d-old slices (Fig. 3, $A$ and $B$ ). Although the superficial cortical slices primarily contain tubule cells, other cell types, e.g. mesangial cells, that express TLR4 may be present. Thus, we isolated tubules and glomeruli separately by a microdissection procedure, and performed a similar RT-PCR analysis for the expression of TLR4 and CD14 in each preparation. Weak, but distinct, bands were observed that showed the presence of both TLR4 and CD14 mRNA in proximal tubule cells prepared from young and adult rats. This result was confirmed by a direct analysis using RNA preparations from RPT cells (data not shown). In contrast, TLR4 and CD14 were not expressed in the glomeruli. The positive controls showed distinct bands for the internal control $\alpha$-tubulin in the glomeruli preparation (Fig. 3C).

\section{DISCUSSION}

Pyelonephritis is more likely to result in renal scarring in infants and young children than in older children and adults. 
A
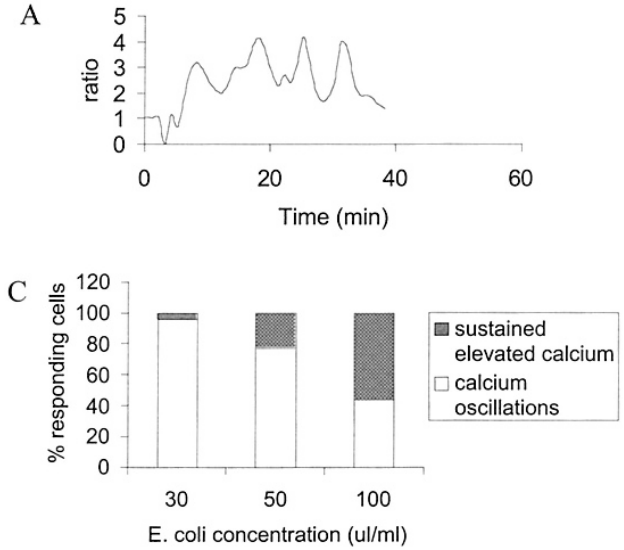
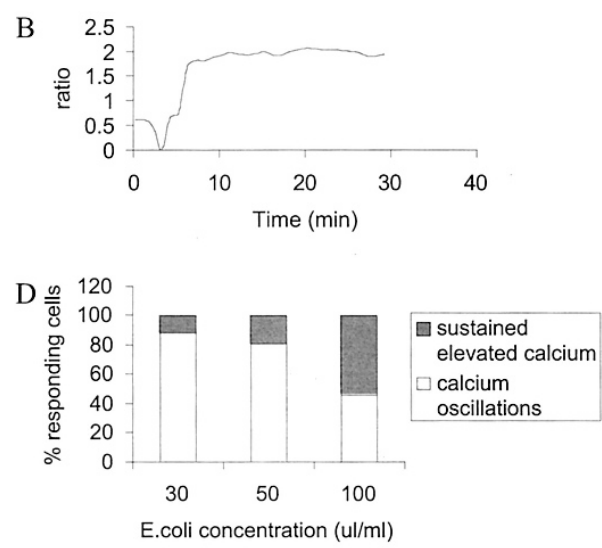

Figure 2. Dose-dependent effect of HlyA-containing E. coli supernatant on intracellular calcium response in RPT cells from 10- and 40-d-old rats. Two types of calcium response were observed, either an oscillating pattern $(A)$ or a sustained increase $(B)$. $C, 10$-d-old RPT cells responding with calcium oscillations $($ open bars) or with sustained calcium (filled bars) in percentage of total number of responding cells. $D, 40$-d-old RPT cells responding with calcium oscillations (open bars) or with sustained calcium (filled bars) in percentage of total number of responding cells. 40-60 cells were examined for each concentration. In most experiments an effect of intracellular calcium was observed in approximately $60 \%$ of cells.

Table 1. Spectral analysis of E. coli supernatant-induced calcium oscillations in 10- and 40-d-old RPT cells

\begin{tabular}{|c|c|c|c|c|c|c|}
\hline \multirow{2}{*}{$\begin{array}{c}\text { Dose } \\
(\mu \mathrm{L} / \mathrm{mL})\end{array}$} & \multicolumn{2}{|c|}{ Peak frequency $(\mathrm{mHz})$} & \multicolumn{2}{|c|}{ Relative power $(\%)$} & \multicolumn{2}{|c|}{ Periodicity (min) } \\
\hline & $10 \mathrm{~d}$ & $40 \mathrm{~d}$ & $10 \mathrm{~d}$ & $40 \mathrm{~d}$ & $10 \mathrm{~d}$ & $40 \mathrm{~d}$ \\
\hline 30 & $1.4 \pm 0.1$ & $1.4 \pm 0.1$ & 55 & 72 & $11.5 \pm 0.8$ & $11.3 \pm 1.0$ \\
\hline 100 & $1.4 \pm 0.1$ & $1.5 \pm 0.3$ & 51 & 43 & $12.0 \pm 1.1$ & $11.1 \pm 1.7$ \\
\hline
\end{tabular}
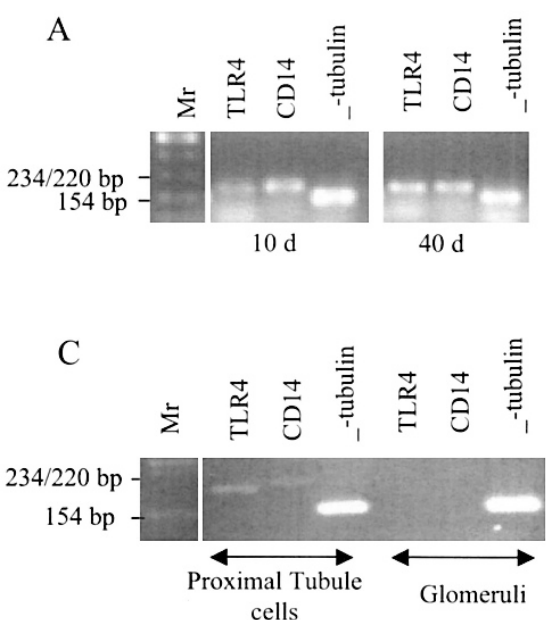

Figure 3. A, RT-PCR shows the expression of TLR4 and CD14 in renal cortical slices from 10- and 40-d-old perfused rat kidneys. Data shown are from PCR run with 28 cycles. The density of the TLR4 and CD14 band was related to that of $\alpha$-tubulin, using Bio-Rad software. $B$, average values are calculated from reactions of 28 and 31 cycles $(n=3$, presented as mean \pm SEM). There were no significant differences between tissue from 10-d and 40-d-old rats $(p>0.1)$. Reactions run at 25 and 35 cycles showed similar results (data not shown) $C$, RT-PCR shows expression of TLR4 and CD14 in microdissected RPT cells and glomeruli from 10-d-old kidneys. The expression was similar in 40-d-old tissues (not shown). Mr, marker.

The results from this experimental study do, however, indicate that the innate immune response of renal epithelial cells is quite well developed postnatally. The two ages used in this study represent infancy and puberty in rats. Renal cortical tissue from infant rats exhibited a lower basal secretion of IL-6 than cells from older rats, but the capacity to induce an IL-6 release on exposure to E. coli culture supernatant was at least as good as in cells from older rats. The expression of TLR4 and CD14, important molecules in the LPS signaling pathway, was similar in both age groups studied. The calcium-signaling pathway in response to E. coli culture supernatant containing HlyA was also similar in both age groups.

The basal level of IL-6 release from 10-d-old renal tissue was approximately $20 \%$ of the basal level found in 40 -d-old renal tissue. Previous studies have shown that the basal cytokine release from blood cells is lower in children than adults, which is consistent with our data $(16,17)$. The capacity of the infant cells to respond to $E$. coli culture supernatant was well developed. This is in concordance with a recent study on Streptococcus agalactiae, showing that mononuclear cells 
from cord and adult blood are equally responsive (18). Exposure of 10-d-old renal tissue to supernatant of bacteria caused a 15-fold increase of IL-6 release compared with a 5-fold increase in 40-d-old renal tissue.

The levels of IL-6 released from 10-d-old cells exposed to bacterial supernatant, however, did not reach the levels observed in 40-d-old cells. Whether this difference in absolute levels of IL-6 release is of importance for the difference in susceptibility to renal scarring remains to be elucidated. The downstream effects of the cytokine release may be considered as a double-edged sword. A moderate cytokine release is crucial to elicit an inflammatory response to clear the infection from the invaded tissue. An overproduction of cytokines can, on the other hand, result in an overreactive inflammatory reaction that could lead to greater tissue damage than necessary to clear the infection.

LPS, the major constituent of the outer membrane of Gramnegative bacteria, is generally considered to be the strongest immunostimulatory agent in bacterial infections. This response is mediated via interaction between LPS and the cellular transmembrane receptor TLR4 (6). Activation of the intracellular signaling pathway eventually leads to nuclear translocation of nuclear factor-kappa B and the concomitant activation of inflammatory response genes such as cytokine genes (19). By use of semiquantitative PCR, we showed that the mRNA expression of TLR4 and the coreceptor CD14 was similar in 10 - and 40-d-old renal cells. The LPS- and IL- $1 \beta$-responsive phenotype of renal TLR4-expressing tissue suggests that the TLR4 signaling pathway is also well developed during infancy. To identify the cellular localization of TLR4 and CD14, we used microdissected proximal tubule segments and glomeruli isolated from perfused kidneys. That experiment clearly showed that TLR4 and CD14 are present in proximal tubular cells but not in the glomeruli. Lack of CD14 expression in the glomeruli fraction shows that the perfusion protocol we used efficiently cleared the tissue from contaminating blood cells, and we can conclude that the TLR4 band indeed originates from proximal tubule cells. This finding is in agreement with recent reports using mouse kidney (20). Furthermore, it indicates that LPS-induced IL-6 release is mainly mediated from renal epithelial cells.

We have previously shown that HlyA secreted from E. coli induces calcium oscillations that can cause the release of IL-6 and IL-8 from RPT cells (7). Here we show that the calcium oscillatory response induced by $30 \mu \mathrm{L} / \mathrm{mL}$ of supernatant from HlyA-expressing E. coli was similar in 10- and 40-d-old cells. HlyA has a dual effect on renal tubule cells. Higher doses of HlyA will result in a sustained calcium response and cell lysis and cell death (21). A sustained calcium response was observed in both 10- and 40-d-old cells when exposed to a high (100 $\mu \mathrm{L} / \mathrm{mL}$ ) supernatant dose. We speculate that, owing to the flushing of urine, it is more likely that the renal tubules will, during the course of infection, be exposed to lower doses of bacterially secreted HlyA. In the situation of urinary tract obstruction or vesicoureteral reflux, the exposure to HlyA may be enhanced. Because large vesicoureteral refluxes are common in infancy and early childhood, exposure to HlyA- expressing E. coli may therefore be more serious during this age period.

The higher susceptibility of pyelonephritic scarring in infancy is likely multifactorial. The infant kidney is immature in many aspects. Anatomic immaturity of the urinary tract probably plays an important role for the response to pyelonephritis. It is well documented that small children have a high incidence of vesicoureteral reflux (3), which should facilitate bacterial deposition in the kidney and may also enhance the exposure to HlyA. Another important aspect may be that the epithelial cell lining in the infant kidney has a higher transepithelial passage than the adult kidney (22). This is a result of a less tight epithelial lining in the urinary tract than in the adult. The tightly linked epithelial cells, present in the fully mature kidney, can be considered as a part of the innate immune system, and may be the strongest defense against invading pathogens. To invade the host tissue, the bacteria must disrupt this barrier. It has been shown that $E$. coli is most adhesive to the basolateral side of the epithelial cell, and rarely to the apical (23). For bacterial invasion it is therefore crucial for the bacteria to disrupt the tight junctions of the epithelial cell lining, most certainly by secreting cytolytic toxins. The less tight epithelial cells in the newborn should therefore facilitate transepithelial invasion of bacteria.

\section{CONCLUSIONS}

In summary, we have shown that many aspects of the intracellular machinery, which participate in innate immune response, are well expressed in the infant rat kidney. We find it unlikely that the quantitative age-dependent differences in IL-6 response observed in the present study can be the only case of the relatively high susceptibility to pyelonephritic renal scarring in infant kidneys. We find it more likely that this high susceptibility to renal scarring is multifactorial and that anatomic immaturity plays a major role.

Acknowledgments. The authors thank Eivor Zettergren Markus, Lill-Britt Svensson, and Ann-Christine Eklöf for excellent experimental assistance.

\section{REFERENCES}

1. Jakobsson B, Berg U, Svensson L 1994 Renal scarring after acute pyelonephritis. Arch Dis Child 70:111-115

2. Ditchfield MR, de Campo JF, Nolan TM, Cook DJ, Grimwood K, Powell HR, Sloane R, Cahill S 1994 Risk factors in the development of early renal cortical defects in children with urinary tract infection. AJR Am J Roentgenol 162:1393-1397

3. Risdon RA 1993 The small scarred kidney in childhood. Pediatr Nephrol 7:361-364

4. Khalil A, Tullus K, Bartfai T, Bakhiet M, Jaremko G, Brauner A 2000 Renal cytokine responses in acute Escherichia coli pyelonephritis in IL- 6-deficient mice. Clin Exp Immunol 122:200-206

5. Godaly G, Proudfoot AE, Offord RE, Svanborg C, Agace WW 1997 Role of epithelial interleukin-8 (IL-8) and neutrophil IL-8 receptor A in Escherichia coli-induced transuroepithelial neutrophil migration. Infect Immun 65:3451-3456

6. Poltorak A, He X, Smirnova I, Liu MY, Huffel CV, Du X, Birdwell D, Alejos E, Silva M, Galanos C, Freudenberg M, Ricciardi-Castagnoli P, Layton B, Beutler B 1998 Defective LPS signaling in $\mathrm{C} 3 \mathrm{H} / \mathrm{HeJ}$ and $\mathrm{C} 57 \mathrm{BL} / 10 \mathrm{ScCr}$ mice: mutations in Tlr4 gene. Science 282:2085-2088

7. Uhlen P, Laestadius A, Jahnukainen T, Soderblom T, Backhed F, Celsi G, Brismar H Normark S, Aperia A, Richter-Dahlfors A 2000 Alpha-haemolysin of uropathogenic E. coli induces $\mathrm{Ca}^{2+}$ oscillations in renal epithelial cells. Nature 405:694-697

8. Brauner A, Katouli M, Tullus K, Jacobson SH 1990 Production of cytotoxic necrotizing factor, verocytotoxin and haemolysin by pyelonephritogenic Escherichia coli. Eur J Clin Microbiol Infect Dis 9:762-767 
9. Siegfried L, Kmetova M, Puzova H, Molokacova M, Filka J 1994 Virulenceassociated factors in Escherichia coli strains isolated from children with urinary tract infections. J Med Microbiol 41:127-132

10. Jacobson SH, Hylander B, Wretlind B, Brauner A 1994 Interleukin-6 and interleukin-8 in serum and urine in patients with acute pyelonephritis in relation to bacterialvirulence-associated traits and renal function. Nephron 67:172-179

11. O'Hanley P, Lalonde G, Ji G 1991 Alpha-hemolysin contributes to the pathogenicity of piliated digalactoside-binding Escherichia coli in the kidney: efficacy of an alpha-hemolysin vaccine in preventing renal injury in the BALB/c mouse model of pyelonephritis. Infect Immun 59:1153-1161

12. Mattsby-Baltzer I, Hanson LA, Kaijser B, Larsson P, Olling S, Svanborg-Eden C 1982 Experimental Escherichia coli ascending pyelonephritis in rats: changes in bacterial properties and the immune response to surface antigens. Infect Immun 35:639-646

13. Bhakdi S, Mackman N, Nicaud JM, Holland IB 1986 Escherichia coli hemolysin may damage target cell membranes by generating transmembrane pores. Infect Immun 52:63-69

14. Larsson S, Aperia A, Lechene C 1986 Studies on final differentiation of rat renal proximal tubular cells in culture. Am J Physiol 251:C455-C464

15. Nishi A, Eklof AC, Bertorello AM, Aperia A 1993 Dopamine regulation of rena $\mathrm{Na}+, \mathrm{K}(+)$-ATPase activity is lacking in Dahl salt-sensitive rats. Hypertension 21:767-771
16. Elsasser-Beile U, Dursunoglu B, Gallati H, Monting JS, von Kleist S 1995 Comparison of cytokine production in blood cell cultures of healthy children and adults. Pediatr Allergy Immunol 6:170-174

17. Bessler H, Komlos L, Punsky I, Ntambi JA, Bergman M, Straussberg R, Sirota L 2001 CD14 receptor expression and lipopolysaccharide-induced cytokine production in preterm and term neonates. Biol Neonate 80:186-192

18. Berner R, Welter P, Brandis M 2002 Cytokine expression of cord and adult blood mononuclear cells in response to Streptococcus agalactiae. Pediatr Res 51:304-309

19. Beutler B 2002 Toll-like receptors: how they work and what they do. Curr Opin Hematol 9:2-10

20. Wolfs TG, Buurman WA, van Schadewijk A, de Vries B, Daemen MA, Hiemstra PS, van 't Veer C 2002 In vivo expression of toll-like receptor 2 and 4 by renal epithelia cells: IFN-gamma and TNF-alpha mediated up-regulation during inflammation. J Immunol 168:1286-1293

21. Laestadius A, Richter-Dahlfors A, Aperia A 2002 Dual effects of Escherichia coli alfa-hemolysin on rat renal proximal tubule cells. Kidney Int 62:2035-2042

22. Horster M, Larsson L 1976 Mechanisms of fluid absorption during proximal tubule development. Kidney Int 10:348-363

23. Wu JH, Billings BJ, Balkovetz DF 2001 Hepatocyte growth factor alters renal epithelial cell susceptibility to uropathogenic Escherichia coli. J Am Soc Nephrol $12: 2543-2553$ 